Jurnal Homepage: http://journal2.um.ac.id/index.php/jaa (p-ISSN: 2087-9695; e-ISSN: 2580-1015)

\title{
Motivasi untuk berbagi pengetahuan ke konsultan pajak
}

\author{
Yonathan Santoso $^{1}$, Legasia Santoso ${ }^{2}$ \\ ${ }^{1}$ Universitas Airlangga, Jl. Airlangga No. 4, Surabaya, Indonesia \\ ${ }^{2}$ Universitas Surabaya, Jl. Tenggilis Mejoyo No. 56, Surabaya, Indonesia
}

Diterima: 8 April 2020

Direvisi: 20 Juli 2020

Disetujui: 21 Juli 2020

\section{Koresponding:}

Yonathan Santoso yonathansantoso6@gmail. com

\section{DOI:}

http://dx.doi.org/10.17977/ um004v7i22020p145

\begin{abstract}
Companies that are short on human resources who have knowledge about taxes tend to hire tax consultants from outside company for company's tax planning. In doing the tax planning, consultants need knowledge of various information to comprehend the characteristics of clients' business. However, sharing knowledge is a dilemma for the company. Sharing knowledge can be an opportunity for new ideas and knowledge but relate to a big risk when the information provided is an important strategy in the company. This study aims to observe the effect of assessment on consultants and accounting and tax knowledge on motivation to share knowledge with tax consultants. By using the data from 113 quetionaires, hypothesis examined by regression analysis. This study revealed that the assessment of consultants would influence the decision to share knowledge. Other factors that originate from outside of their relationship that is the client's accounting knowledge and tax do not have an important role in explaining the decision to share that knowledge. The results of this study are expected to be a consideration for regulators and related agencies in order to improve the relationship between clients and tax consultants in order to provide convenience in carrying out corporate taxation strategies.

Keywords: Knowledge Sharing; Tax Consultant; Tax Planning; Value of Tax Consultant; Accounting and Tax Knowledge
\end{abstract}

\begin{abstract}
Abstrak
Perusahaan yang kekurangan sumber daya manusia yang memiliki pengetahuan tentang pajak cenderung mempekerjakan konsultan pajak dari luar perusahaan untuk kebutuhan perencanaan pajak perusahaan. Dalam melakukan perencanaan pajak tersebut, konsultan membutuhkan pengetahuan berbagai informasi untuk mengetahui karakteristik bisnis klien. Namun, berbagi pengetahuan menjadi sebuah dilema bagi perusahaan. Berbagi pengetahuan dapat menjadi peluang untuk memunculkan ide dan pengetahuan baru, tetapi juga berisiko besar ketika informasi yang diberikan merupakan strategi penting perusahaan. Penelitian ini bertujuan untuk mengetahui pengaruh penilaian kepada konsultan dan pengetahuan akuntansi dan pajak terhadap motivasi untuk berbagi pengetahuan ke konsultan pajak. Dengan menggunakan data survei dari 113 kuesioner, pengujian hipotesis dilakukan dengan analisis regresi. Hasil penelitian ini mengungkapkan bahwa penilaian terhadap konsultan akan mempengaruhi keputusan untuk berbagi pengetahuan. Faktor lain yang berasal dari luar hubungan klien dan konsultan yaitu pengetahuan akuntansi dan pajak klien yang tidak memiliki penting dalam menjelaskan keputusan berbagi pengetahuan tersebut. Hasil dari penelitian ini diharapkan menjadi sebuah pertimbangan bagi pembuat keputusan dan instansi terkait agar dapat memperbaiki hubungan antara klien dan konsultan pajak sehingga dapat memberikan kemudahan dalam melakukan strategi perpajakan perusahaan.

Kata Kunci: Berbagi Pengetahuan; Konsultan Pajak; Perencanaan Pajak; Penilaian terhadap Konsultan Pajak; Pengetahuan Akuntansi dan Pajak
\end{abstract}

\section{PENDAHULUAN}

Perpajakan tidak terpisahkan dari sebuah negara karena sumber pendapatan terbesar berasal dari sektor pajak (Putra et al., 2020). Pendapatan dari pajak digunakan untuk pembangunan di berbagai bidang. Lingkungan pajak perusahaan yang kompleks menuntut perusahaan untuk terus mengikuti perkembangan dunia perpajakan secara fleksibel dan cepat dengan tetap patuh dalam menghadapi tantangan berikutnya (Glaister \& Hughes, 2008). Perusahaan akan mulai mempekerjakan ahli dari luar persusahaan yang memiliki pengetahuan lebih baik dalam perencanaan (Mulligan \& Oats, 2016). Ketika hal tersebut terjadi, konsultan sebagai ahli dari eksternal sering terlibat dalam dua fungsi utama yaitu sebagai ahli dari perencanaan perpajakan perusahaan dan meminimalisir risiko perpajakan (Frecknall-Hughes \& Kirchler, 2015; Van der Rijt et al., 2019). Namun, klien mungkin 
menyadari adanya potensi konflik kepentingan ketika memberikan informasi tentang perusahaan kepada konsultan pajak perusahaan.

Penelitian ini dilakukan sebagai upaya untuk memperbaiki hubungan konsultan pajak dan klien serta mengurangi keraguan klien kepada konsultan pajak, terutama dalam mengikuti perubahan peraturan perpajakan yang semakin kompleks. Konsultan pajak membutuhkan informasi dari perusahaan agar fungsi dan peran konsultan pajak dapat berjalan dengan baik. Fungsi konsultan pajak dalam meningkatkan kepatuhan wajib pajak dan jumlah pajak disetor menjadi penting karena jumlah pemasukan negara dari sektor pajak menjadi prioritas utama.

Klien kemungkinan membatasi tingkat pengetahuan, hubungan dan informasi yang diberikan kepada konsultan pajak. Peran konsultan pajak disini mulai menjadi masalah ketika konsultan pajak harus mempelajari bisnis dan usaha klien untuk membuat perencanaan yang baik namun klien tidak memiliki kepercayaan terhadap konsultan pajak. Hal tersebut membuat konsultan pajak harus mencari cara untuk meningkatkan kepercayaan klien.

Pengetahuan bagi klien dianggap sebagai sumber daya dan aset tidak berwujud sehingga informasi perusahaan terutama terkait dengan strategi perusahaan cenderung untuk dirahasiakan (Davenport \& Prusak, 1998; Kombih \& Suhardianto, 2018; Pratomo, 2017; Van der Rijt et al., 2019). Tindakan pembatasan dari klien ini membuat konsultan pajak harus berpikir jauh dalam hal perencanaan pajak. Konsultan pajak merasa kesulitan ketika pengetahuan dibatasi oleh klien sedangkan klien menuntut lebih besar dari yang konsultan pajak. Hal positif yang akan diperoleh perusahaan ketika perusahaan membagikan pengetahuan berdampak lebih besar dari risiko tersebut. Inovasi baru yang berasal dari pengetahuan konsultan pajak akan dieksploitasi oleh perusahaan sehingga ini menjadi pertimbangan baik bagi perusahaan (Van den Hooff \& Huysman, 2009; Van der Rijt et al., 2019). Perusahaan harus mulai mempertimbangkan manfaat yang akan diperoleh yaitu informasi perpajakan dan inovasi baru. Proses berbagi pengetahuan ini dianggap sebagai cara agar perusahaan dapat memperoleh keunggulan yang kompetitif dan ide-ide baru yang memiliki "valueadded benefits" (Argote \& Ingram, 2000; Liebowitz, 2001; C.-C. Wang \& Yang, 2007).

Penelitian sebelumnya tentang berbagi pengetahuan pada umumnya hanya melihat hubungan individu dengan individu lain dalam satu tim, divisi atau sebuah kelompok. Penelitian tentang berbagi pengetahuan antara pihak internal dengan eksternal masih jarang diteliti terutama antara klien dengan konsultan pajak. Penelitian terkait berbagi pengetahuan yang pernah diteliti dengan melihat pihak internal dan eksternal sebagian besar hanya berfokus pada efek dari pengetahuan yang diberikan dan keunggulan kinerja antara klien dengan auditor eksternal perusahaan (Bonner, 1990; Brown et al., 2016; Sila et al., 2016) padahal peran konsultan pajak dalam bisnis klien juga semakin membentuk ikatan yang kuat (Krackhardt, 1992). Berbagi pengetahuan akan timbul dari adanya keinginan dan timbal balik untuk menanggapi pengetahuan yang diberikan baik berupa ilmu maupun informasi baru (Orr, 2016).

Temuan sebelumnya terkait nilai dengan berbagi pengetahuan menunjukkan adanya perbedaan. Borgatti dan Cross (2003) menemukan bahwa penilaian terhadap individu akan memengaruhi proses berbagi pengetahuan. Ketika individu cenderung memberikan penilaian yang tinggi kepada individu yang lain, maka interaksi dan transfer pengetahuan akan sering dilakukan. Hasil tersebut juga didukung oleh penelitian Choi dkk. (2010). Hasil berbeda ditunjukkan oleh Ko (2010) yang menyebutkan bahwa nilai kompetensi seorang konsultan yang diyakini oleh klien tidak akan memengaruhi kecenderungan berbagi pengetahuan. Hal ini disebabkan klien cenderung memberikan informasi yang dimiliki dikarenakan durasi waktu interaksi. Ketika hubungan yang terjalin antara klien dan konsultan pajak dalam waktu yang cukup lama dan banyak interaksi yang terjadi, maka tingkat kepercayaan bisa berkembang dan justru melemahkan informasi yang dianggap sebagai aset bagi perusahaan. Klien dan konsultan dianggap memiliki sifat yang berkelanjutan tanpa melihat kompetensi dari konsultan perusahaan (Glückler \& Armbrüster, 2003).

Social Cognitive Theory (Teori Kognitif Sosial) adalah teori yang dipakai dalam penelitian ini. Teori ini digunakan karena dinilai relevan dengan hubungan antara variabel independen dan dependen. Teori ini mengakui adanya faktor-faktor dalam diri manusia untuk berpikir dan mempelajari sesuatu sehingga membuat sebuah tindakan, motivasi dan emosi dari individu tersebut (Bandura \& Walters, 1977). Sejalan dengan pemikiran tersebut, teori ini memandang kemampuan mengatur diri ada dalam setiap individu dan dipengaruhi oleh adanya jaringan sosial seseorang (Chiu et.al., 2006). Semakin baik jaringan yang dibentuk, maka semakin besar keinginan seseorang untuk belajar. Proses berbagi pengetahuan akan berjalan ketika jaringan yang dibentuk oleh kedua individu berinteraksi dengan baik. 
Penelitian ini bertujuan untuk melihat pengaruh penilaian konsultan dan pengetahuan akuntansi dan pajak terhadap berbagi pengetahuan kepada konsultan pajak. Penelitian ini dilakukan karena penelitian mengenai berbagi pengetahuan yang telah ada sebelumnya cenderung meneliti hubungan antara tim, kelompok dan golongan. Interaksi dengan pihak luar termasuk konsultan dan klien perusahaan, terutama penelitian tentang interaksi antara pihak internal perusahaan dengan konsultan pajak ini belum pernah dilakukan di Indonesia. Penelitian ini akan berfokus kepada hubungan antara pengetahuan akuntansi dan pajak dari klien dengan berbagi pengetahuan kepada konsultan pajak. Penelitian ini diharapkan dapat mengurangi keraguan klien terhadap konsultan pajak sehingga klien mau berbagi pengetahuan kepada konsultan pajak. Dengan demikian, perencanaan pajak perusahaan diharapkan dapat berjalan dengan baik.

\section{Penilaian terhadap Konsultan Memengaruhi Berbagi Pengetahuan kepada Konsultan Pajak}

Ketakutan klien terhadap konsultan pajak terutama dalam berbagi informasi yang dimiliki klien menjadi sebuah dilema yang mempersulit tugas dan fungsi dari konsultan pajak (Dewi et al., 2019). Terdapat kemungkinan bahwa konsultan pajak mengambil keuntungan sendiri dari informasi yang dimiliki oleh organisasi lain dimana hal ini menjadi batasan dan masih sering terjadi. Kepercayaan yang dibangun diantara klien dan konsultan masih sebatas profesi dan mendiskusikan masalah yang umum. Pada dasarnya, penilaian akan menjadi dasar kepercayaan atau keyakinan dari pikiran kepada objek dan menghasilkan sebiuah tindakan (Suharyat, 2009). Semakin besar penilaian, maka kondisi tersebut dapat menentukan semakin besar keyakinan kepada orang lain.

Penelitian sebelumnya tentang pengaruh penilaian terhadap keputusan berbagi informasi menunjukkan bahwa penilaian mempengaruhi tindakan tersebut (Borgatti \& Cross, 2003; Choi et al., 2010; Hau et al., 2013; Van der Rijt et al., 2019). Namun, penelitian oleh Glückler dan Armbrüster (2003) menunjukkan hubungan klien dan konsultan akan berlanjut kepada berbagi informasi yang lebih ketika muncul pengalaman yang positif. Hubungan klien dan konsultan tidak mempertimbangkan penilaian terkait kompetensi diantara kedua belah pihak tersebut. Pengalaman positif tersebut cenderung meleburkan ketidakpercayaan kepada konsultan pajak dan cenderung memperkuat hubungan interaksi kedua pihak. Ko (2010) juga sependapat terhadap pernyataan tersebut. Dari perbedaan penelitian, penelitian ini akan meneliti kembali untuk memperjelas pengaruh diantara kedua pihak tersebut dengan membuat hipotesis sebagai berikut:

$\mathrm{H}_{1}$ : Penilaian terhadap konsultan mempengaruhi keputusan berbagi pengetahuan ke konsultan pajak.

\section{Pengetahuan Akuntansi dan Pajak Mempengaruhi Berbagi Pengetahuan kepada Kon- sultan Pajak}

Pengetahuan tidak hanya diperoleh dari pendidikan namun dari berbagai sumber. Hayes et al. (2018) berpendapat bahwa hasil gelar sarjana di Australia tidak dapat sepenuhnya menyiapkan lulusan yang sesuai dengan profesi. Hal tersebut menunjukkan bahwa masih banyak faktor lain yang bisa meningkatkan pengetahuan seperti pelatihan atau dari pengalaman khusus. Ketika sesorang bekerja sesuai dengan pengetahuan, maka akan menciptakan hasil yang lebih baik daripada orang yang tidak memiliki pengetahuan di bidang pekerjaan yang dijalankan (Herawaty \& Susanto, 2008).

Secara luas, Blomkvist et al., (2016) menunjukkan bahwa perusahaan yang memiliki tingkat inovasi yang tinggi akan membutuhkan manajemen yang berkompeten secara pengetahuan. Perusahaan akan cenderung mencari pengetahuan dari pihak eksternal ketika tidak memperoleh sumber pengetahuan dari internal (Chesbrough, 2012; Chiang \& Hung, 2010; Grönlund et al., 2010). Ketika karyawan dari sebuah perusahaan tidak memiliki pengetahuan perpajakan yang memadai maka perusahaan cenderung mempekerjakan konsultan pajak untuk mencapai tujuan. Dalam penelitian-penelitian tersebut ditemukan bahwa ketika perusahaan hanya memiliki sedikit karyawan yang memiliki pengetahuan dan keterampilan di bidang akuntansi, maka manajemen perusahaan cenderung memberikan saran untuk berbagi pengetahuan ke pihak eksternal. Dari pernyataan tersebut, dikembangkan hipotesis sebagai berikut:

$\mathrm{H}_{2}$ : Pengetahuan informan di bidang akuntansi dan pajak mempengaruhi keputusan berbagi pengetahuan ke konsultan pajak. 


\section{METODE}

Penelitian ini akan menggunakan metode pendekatan kuantitatif. Jenis penelitian adalah kausal komperatif yang menguji sebab dan akibat dengan menggunakan teori yang relevan (Sugiyono, 2006). Data yang digunakan dalam penelitian ini adalah data primer yang diperoleh dengan cara menyebarkan kuesioner yang didistribusikan langsung oleh peneliti kepada responden. Jawaban responden dalam kuisioner yang disebarkan akan menjadi data yang digunakan dalam meneliti hipotesis yang diajukan terkait keputusan untuk berbagi pengetahuan ke konsultan pajak. Kuesioner dalam penelitian ini didistribusikan sebanyak 120 kuesioner yang ditujukan kepada partisipan dengan tingkat pengembalian sebanyak 120 kuisioner. Data yang dapat diolah sebanyak 113 kuesioner dengan kriteria perusahaan yang menggunakan jasa konsultan pajak eksternal.

\section{Definisi Operasional dan Pengukuran Variabel}

Variabel independen dalam penelitian ini yaitu penilaian terhadap konsultan serta pengetahuan akuntansi dan pajak klien. Variabel dependen yang digunakan adalah berbagi pengetahuan. Untuk menjawab penelitian ini, digunakan skala likert 5 poin dalam kuesioner.

\section{Berbagi pengetahuan (knowledge sharing)}

Berbagi pengetahuan (knowledge sharing) adalah sebuah tindakan atau perilaku untuk menciptakan pertukaran pengetahuan atau transfer memori ke orang lain dengan interaksi untuk membahas dan mencapai sebuah tujuan organisasi (Dyer \& Nobeoka, 2000). Berbagi pengetahuan akan memberikan kesempatan untuk menimbulkan sebuah ide-ide baru (Lumbantobing, 2011). Penelitian ini menggunakan dua indikator dalam mengukur variabel berbagi pengetahuan.

\section{Penilaian terhadap konsultan}

Nilai adalah sebuah keyakinan terkait baik atau buruknya sebuah objek yang diamati (Rokeach, 1968). Dasar dari keyakinan tersebut akan menjadi sebuah kebenaran bagi penilai dan merupakan hasil dari penilaian. Variabel penilaian dalam penelitian ini akan diukur dengan menggunakan tiga indikator.

\section{Pengetahuan akuntansi dan pajak klien}

Nonaka dan Teece (2001) mengartikan pengetahuan sebagai informasi yang berisi kemampuan, intuisi, pengalaman, pendapat dan motivasi yang berasal dari sumber yang dapat dipercaya dan menjadi sebuah kebenaran bagi sebagian besar manusia. Makna dari pengetahuan adalah kumpulan dari berbagai informasi yang menjadi sebuah komponen mental dari pengalaman. Pengetahuan yang akan dibahas dalam penelitian ini terkait dengan pengetahuan akuntansi dan pajak. Variabel tersebut akan diukur dengan menggunakan dua indikator. Analisis dalam penelitian ini akan menggunakan regresi linier berganda dengan model sebagai berikut:

$$
Y=\alpha+\beta_{1} X_{1}+\beta_{2} X_{2}+e
$$

Keterangan:

$\begin{array}{ll}\mathrm{Y} & =\text { Berbagi Informasi } \\ \alpha & =\text { Konstanta } \\ \beta_{1}, \beta_{2} & =\text { Koefisien Regresi Variabel Independen } \\ \mathrm{X}_{1} & =\text { Variabel Penilaian Terhadap Konsultan } \\ \mathrm{X}_{2} & =\text { Variabel Pengetahuan Akuntansi dan Pajak } \\ \mathrm{e} & =\text { Error }\end{array}$

\section{HASIL DAN PEMBAHASAN}

Data diperoleh dari kuesioner berbagai perusahaan yang memenuhi kriteria dengan responden yang terdiri dari 54 partisipan laki-laki dan 59 partisipan perempuan. Hal tersebut dikarenakan tujuh data dari 200 kuesioner yang dikembalikan menyatakan bahwa partisipan tidak pernah berhubungan langsung dengan konsultan pajak yang dipekerjakan di perusahaan klien sehingga tidak dapat menjadi data yang terkait dengan penelitian. Penyajian responden tersaji di Tabel 1. 
Tabel 1. Komposisi Jenis Kelamin Partisipan

\begin{tabular}{ccc}
\hline Jenis Kelamin & Banyaknya Partisipan & Persentase (\%) \\
\hline Laki-laki & 54 & 47,8 \\
Perempuan & 59 & 52,2 \\
Total & 113 & 100 \\
\hline
\end{tabular}

Tabel 2. Komposisi Tingkat Pendidikan Partisipan

\begin{tabular}{ccc}
\hline Pendidikan & Banyaknya Partisipan & Presentase(\%) \\
\hline SMA/SMK & 21 & $18,6 \%$ \\
D3/S-1 & 86 & $76,1 \%$ \\
S-2 & 4 & $3,5 \%$ \\
S-3 & 2 & $1,8 \%$ \\
\hline
\end{tabular}

Tabel 3. Hasil Pengujian Hipotesis

\begin{tabular}{cccccc}
\hline & t hitung & t tabel & Sig. & Keterangan \\
\hline $\begin{array}{c}\text { Penilaian konsul- } \\
\tan \left(\mathrm{X}_{1}\right)\end{array}$ & 4,905 & 1,65909 & 0,000 & 0,05 & H1 diterima \\
$\begin{array}{c}\text { Pengetahuan } \\
\text { akuntansi dan } \\
\text { pajak }\left(\mathrm{X}_{2}\right)\end{array}$ & 1,389 & 1,65909 & 0,168 & 0,05 & H2 ditolak \\
\hline
\end{tabular}

Tabel 4. Hasil Uji F

\begin{tabular}{ccccc}
\hline Model & df & $\begin{array}{c}\text { Mean } \\
\text { Square }\end{array}$ & $\mathbf{F}_{\text {hitung }}$ & Ftabel \\
\hline Regression & 2 & 7,245 & 15,594 & 3,930 \\
Residual & 110 & 0,645 & & \\
Total & 112 & & & \\
\hline
\end{tabular}

Tabel 5. Uji Koefisien Determinasi

\begin{tabular}{ccccc}
\hline Model & R & R Square & $\begin{array}{c}\text { Adjusted } \\
\text { R Square }\end{array}$ & $\begin{array}{c}\text { Std. Error of the } \\
\text { Estimate }\end{array}$ \\
\hline 1 &, $470^{\mathrm{a}}$ & 0,221 & 0,207 & 0,68163 \\
\hline
\end{tabular}

Selanjutnya, tingkat pendidikan partisipan yang mengisi kusioner ini terdiri dari lulusan SMA/SMK sebanyak 21 partisipan (18,6\%), lulusan D3/S1 sebanyak 86 partisipan (76,1\%), lulusan S2 sebanyak empat partisipan (3,5\%), lulusan S3 sebanyak dua partisipan (1,8\%). Tabel 2 tersebut menyajikan diskripsi tingkat pendidikan responden.

Pengukuran validitas dari setiap instrumen penelitian ini menggunakan indeks korelasi product moment. Dari pengujian validitas dalam setiap pertanyaan dinyatakan bahwa setiap instrumen dalam penelitian ini menyatakan $\mathrm{R}_{\text {hitung }}$ lebih besar dari $\mathrm{R}_{\text {tabel }}$ sehingga dapat disimpulkan bahwa instrumen penelitian memenuhi persyaratan valid terhadap penelitian ini. $\mathrm{R}_{\text {tabel }}$ yang diperoleh sebesar 0,15 dengan setiap indeks korelasi product moment lebih besar sehingga hasil uji validitas dari setiap instrumen dinyatakan valid. Hasil uji realibilitas dalam penelitian ini terlihat dari nilai Cronbach's Alpha dalam tiap variabel yang lebih besar dari 0,5 sehingga memenuhi persyaratan (Azwar, 2001).

Uji normalitas dilakukan kepada setiap variabel dalam penelitian ini. Grafik normal probability plot menunjukkan bahwa distribusi data normal karena menyebar di sepanjang garis diagonal. Dalam penelitian ini, nilai Inflating Factors (VIF) penilaian terhadap konsultan pajak sebesar 1,064 dan pengetahuan akuntansi dan pajak sebesar 1,064. Nilai tersebut menunjukkan bahwa tidak terjadi multikolinearitas diantara variabel karena nilai VIF kurang dari 10. Uji heteroskedastisitas dalam penelitian ini menggunakan Uji Glejser menghasilkan bahwa tidak heterokedastisitas pada model regresi tersebut karena nilai nilai signifikansi lebih besar dari 0,05 dan besar $t_{\text {hitung }}$ kurang dari $t_{\text {tabel }}$. Hasil ini juga ditunjukkan bahwa titik scatterplot menyebar secara acak dan tidak membentuk sebuah pola tertentu. 
Selanjutnya, tabel ringkasan hasil pengujian hipotesis disajikan pada Tabel 3. Hasil pengujian sebagaimana tersaji di Tabel 3 menunjukkan bahwa variabel penilaian konsultan memengaruhi keputusan untuk berbagi pengetahuan ke konsultan pajak dengan $t_{\text {hitung }}$ sebesar 4,905 lebih besar dari $t_{\text {tabel }}$ yang menunjukkan angka sebesar 1,65909 dan tingkat signifikansi sebesar 0,000 kurang dari 0,05. Sehubungan dengan itu, maka hipotesis 1 dalam penelitian ini diterima.

Untuk variabel pengetahuan akuntansi dan pajak menunjukkan angka thitung yang lebih kecil dari ttabel dengan nilai $t_{\text {hiung }} 1,389$ dan $t_{\text {tabel }}$ 1,65909. Nilai signifikasi untuk variabel pengetahuan akuntansi dan pajak bernilai 0,168 yang berarti lebih besar dari 0,05. Dari paparan tersebut dapat disimpulkan bahwa Hipotesis 2 dalam penelitian ini ditolak.

Uji simultan dalam penelitian ini seperti tampak di Tabel 4 menunjukkan angka $\mathrm{F}_{\text {hitung }}$ sebesar 15,594. Nilai tersebut lebih besar dari nilai $F_{\text {tabel }}$ sebesar 3,93. Sehingga model pengujian simultan penilaian konsultan dan pengetahuan akuntansi dan pajak berpengaruh terhadap berbagi pengetahuan ke konsultan pajak.

Sedangkan Tabel 5 menjelaskan besarnya koefisien determinasi variabel independent terhadap variabel dependen pada penelitian ini menunjukkan nilai 22\%. Artinya, variabel penilaian konsultan dan pengetahuan akuntansi dan pajak memiliki kuat pengaruh sebesar $22 \%$ terhadap perilaku berbagi pengetahuan ke konsultan pajak.

Berdasarkan hasil pengujian hipotesis menunjukkan bahwa Social Cognitive Theoryterkait dua jenis kognitif manusia yang ditunjukkan oleh Bandura (1989) menjadi faktor yang mendukung dalam tindakan klien untuk berbagi pengetahuan kepada konsultan pajak. Wang \& Noe (2010) menyebutkan bahwa terdapat lima kelompok faktor yang dapat memengaruhi kesediaan seseorang untuk berbagi pengetahuan yaitu budaya nasional, konteks organisasi, karakteristik antar tim, karakteristik individu, dan faktor yang memotivasi.

Keyakinan sebagai faktor yang membuat motivasi dan menjadi sebuah penentu penilaian terhadap konsultan pajak tersebut dapat dipercaya, berkompeten dan dapat menjaga rahasia perusahaan. Klien yang memberikan penilaian yang baik terkait dengan kinerja konsultan pajak akan semakin mempekerjakan konsultan pajak tersebut terutama terkait keputusan-keputusan strategis perusahaan. Penilaian ini mengurangi rasa keraguan klien terhadap konsultan seiring berjalannya interaksi. Hasil ini sejalan dengan penelitian Borgatti \& Cross (2003) yang menunjukkan bahwa penilaian menjadi faktor yang penting dalam berbagi pengetahuan.

Hipotesis pertama menunjukkan bahwa penilaian dapat memengaruhi berbagi pengetahuan. Klien akan memberikan pengetahuan yang dimiliki ketika klien yakin terhadap objek yang berinteraksi dengannya. Self-efficacy juga menjadi penentu ketika tidak hanya sekedar mengetahui pengetahuan yang diberikan tetapi juga mengukur tingkat kepentingan tindakan tersebut (Bandura, 1986; Tarsidi, 2010). Ketika individu memiliki keterampilan dan pengetahuan atas informasi tersebut maka individu tersebut akan melihat seberapa penting dan akibat yang timbul jika informasi tersebut diberikan ke orang lain. Dengan pengetahuan akuntansi dan pajak klien, individu tersebut akan mengukur prinsip-prinsip yang dianggap penting dan merupakan aset perusahaan yang berharga sehingga klien mungkin akan menutup diri untuk membagikan informasi tersebut terutama pada pihak eksternal yaitu konsultan pajak. Hubungan interaksi antara klien dan konsultan pajak membuat klien semakin memahami dan menilai baik konsultan pajak yang dimiliki perusahaan. Penilaian akan menjadi lebih baik ketika persepsi klien menimbulkan sebuah keyakinan atas objek yaitu konsultan pajak perusahaan dari berbagai aspek yang menjadi indikator. Klien mempelajari faktor-faktor dalam diri konsultan pajak dan menciptakan sebuah harapan agar tujuan dari perusahaan dapat tercapai seperti inovasi dan ide-ide baru.

Klien harus berhati-hati dalam menilai seorang konsultan pajak. Dalam membagikan pengetahuan yang menjadi keunggulan atau strategi perusahaan, klien justru akan melihat nilai dari konsultan. Terdapat kemungkinan bahwa klien menghargai konsultan sebagai sumber tambahan pengetahuan tetapi klien juga harus menilai sejauh mana dapat mempercayai konsultan pajak tersebut untuk menjaga rahasia perusahaan. Proses berbagi pengetahuan tersebut menuntut tanggung jawab yang besar terhadap klien karena kurangnya kepercayaan. Kondisi ini menunjukkan seolah konsultan pajak hanya berperan dalam kewajiban perpajakan dan sampai ke dalam perencanaan pajak. Ketika klien menilai peran konsultan hanya sebatas hal tersebut, maka sangat sulit tercipta transfer pengetahuan.

Hipotesis kedua dalam penelitian ini ditolak. Hasil ini menunjukkan bahwa pengetahuan akuntansi dan pajak dari klien tidak berpengaruh terhadap berbagi pengetahuan ke konsultan pajak. Pengetahuan akuntasi dan pajak dari klien yang besar tidak menunjukkan dampak terhadap keinginan untuk berbagi pengetahuan. Hasil ini sejalan dengan penelitian Glückler \& Armbrüster (2003) bahwa interaksi yang bersifat berkelanjutan akan membuat seseorang terus berbagi pengetahuan yang dimiliki 
tanpa melihat faktor lain yang memengaruhi kepercayaan. Hubungan antara klien dan konsultan terutama ketika kedua pihak tersebut terlibat dalam sebuah proyek jangka panjang sehingga klien tetap membagikan informasi perusahaan tanpa melihat seberapa penting dari informasi tersebut bagi perusahaan. Klien yang ahli dalam bidang akuntansi dan pajak tidak cenderung untuk membatasi diri untuk membagikan informasi yang dianggap rahasia dan strategi perusahaan. Peran konsultan pajak lebih kepada partner klien dalam membahas masalah perpajakan dan justru semakin memberikan hubungan timbal balik transfer pengetahuan.

Kemungkinan kedua adalah adanya kedekatan fisik terhadap kesamaan ras, jenis kelamin, dan usia. Brass (2003) menunjukkan bahwa orang yang memiliki kesamaan atribut atau homopily akan cenderung berinteraksi lebih kuat. Kesamaan tersebut akan membuat hubungan klien dan konsultan pajak menjadi lebih baik. Pengetahuan akuntansi dan pajak yang dimiliki klien tidak akan membatasi kecenderungan untuk berbagi pengetahuan karena interaksi di antara kedua pihak lebih kuat.

Kemungkinan ketiga adalah tuntutan dari perusahaan agar berbagi informasi yang dibutuhkan konsultan pajak yang membuat klien justru membagikan informasi tersebut. Sebagian besar perusahaan justru menginginkan pembayaran pajak yang rendah sehingga perusahaan ingin konsultan pajak terlibat aktif dalam perencanaan pajak bersama dengan pekerja internal. Dalam melakukan perencanaan tersebut, pekerja internal dituntut untuk membagikan segala informasi yang diberikan meskipun mereka memiliki pengetahuan yang tinggi di bidang akuntansi dan pajak dan mengetahui bahwa informasi tersebut cenderung berisiko ketika diketahui orang luar perusahaan. Kemungkinan ditolaknya hipotesis kedua yang dipaparkan di atas menunjukkan bahwa Social Cognitive Theory dapat menjawab keinginan untuk berbagi pengetahuan ketika hubungan antara klien dan konsultan berdasarkan tiga kemungkinan tersebut yang membuat klien belajar dan meyakini bahwa konsultan pajak perusahaan adalah orang yang dapat dipercaya sehingga pembelajaran yang baik dan berdurasi lama terhadap objek berpengaruh terhadap berbagi pengetahuan.

\section{SIMPULAN}

Penelitian ini menghasilkan temuan bahwa penilaian terhadap konsultan pajak memengaruhi perilaku untuk berbagi pengetahuan ke konsultan pajak. Sebaliknya, pengetahuan akuntansi dan pajak tidak memengaruhi perilaku untuk berbagi pengetahuan ke konsultan pajak.

Keterbatasan dalam penelitian ini terkait dengan bias jawaban responden, yaitu pihak perusahaan. Untuk itu, penelitian berikutnya disarankan menjelaskan serangkaian faktor eksternal yang memengaruhi perilaku berbagi pengetahuan ke konsultan pajak. Sekaligus menggali faktor resiko yang timbul jika membagikan pengetahuan perusahaan ke konsultan pajak. Penelitian berikutnya juga dapat menguji alasan perusahaan menggunakan jasa konsultan pajak dan pengaruhnya terhadap keputusan untuk berbagi pengetahuan.

Adapun, implikasi penelitian ini bagi konsultan pajak dalam rangka mengurangi keraguan perusahaan terhadap profesi konsultan adalah meningkatkan kualitas diri profesi konsultan pajak dan menjaga kerjasama yang saling memberikan manfaat. Sebaliknya, perusahaan diharapkan lebih terbuka dalam memberikan informasi perusahaan ke konsultan pajak dalam rangka memperoleh pengetahuan pajak, agar dapat merencanakan pajak secara efektif.

\section{DAFTAR RUJUKAN}

Argote, L., \& Ingram, P. (2000). Knowledge transfer: A basis for competitive advantage in firms. Organizational Behavior and Human Decision Processes, 82(1), 150-169. doi:10.1006/ obhd.2000.2893.

Azwar, S. (2001). Reliabilitas dan validitas SPSS. Yogyakarta:Pustaka Pelajar.

Bandura, A. (1986). The explanatory and predictive scope of self-efficacy theory. Journal of social and clinical psychology, 4(3), 359-373. doi:10.1521/jscp.1986.4.3.359.

Bandura, A. (1989). Human agency in social cognitive theory. American psychologist, 44(9), 1175. doi:10.1037/0003-066x.44.9.1175.

Bandura, A., \& Walters, R. H. (1977). Social learning theory (Vol. 1). New Jersey: Prentice-hall Englewood Cliffs.

Blomkvist, M., Johansson, J., \& Malmström, M. (2016). Accounting Knowledge in Innovative Firms: Direct Contacts with External Auditors for Strategic Actions. International Journal of Managerial and Financial Accounting, 8(3/4), 209-228. doi:10.1504/IJFMA.2016.08.081852. 
Bonner, S. E. (1990). Experience Effects in Auditing: The Role of Task-Specific Knowledge. Accounting Review, 72-92.

Borgatti, S. P. \& Cross, R. (2003). A Relational View of Information Seeking and Learning in Social Networks. Management Science, 49(4), 432-445. doi:10.1287/mnsc.49.4.432.14428.

Brass, D. J. (2003). A Social Network Perspective on Human Resources Management. Networks in the Knowledge Economy. New York: Oxford University Press.

Brown, V. L., Gissel, J. L., \& Neely, D. G. (2016). Audit Quality Indicators: Perceptions of JuniorLevel Auditors. Managerial Auditing Journal, 31(8/9), 949-980. doi:10.1108/MAJ-01-2016-1300.

Calantone, R. J., Kim, D., Schmidt, J. B., \& Cavusgil, S. T. (2006). The Influence of Internal and External Firm Factors on International Product Adaptation Strategy and Export Performance: A Three-Country Comparison. Journal of Business Research, 59(2), 176-185. doi:10.1016/j. busres.2005.05.001.

Chesbrough, H. (2012). Open Innovation: Where We've Been and Where We're Going. ResearchTechnology Management, 55(4), 20-27. doi:10.5437/08956308X5504085.

Chiang, Y. H. \& Hung, K. P. (2010). Exploring Open Search Strategies and Perceived Innovation Performance from The Perspective of InterOrganizational Knowledge Flows. R\&D Management, 40(3), 292-299. doi:10.1111/j.1467-9310.2010.00588.x.

Chiu, C.-M., Hsu, M.-H., \& Wang, E. T. (2006). Understanding Knowledge Sharing in Virtual Communities: An Integration of Social Capital and Social Cognitive Theories. Decision Support Systems, 42(3), 1872-1888. doi:10.106/j.dss2006.04.001.

Choi, S. Y., Lee, H., \& Yoo, Y. (2010). The Impact of Information Technology and Transactive Memory Systems on Knowledge Sharing, Application, and Team Performance: A Field Study. MIS quarterly, 34(4), 855-870. doi:10.2307/25750708

Davenport, T. H. \& Prusak, L. (1998). Working Knowledge: How Organizations Manage What They Know. Massachussets: Harvard Business Press.

Dewi, A. A. I. P., Sudarma, M., \& Baridwan, Z. (2019). Mengupas Bentuk Dilema dari Sisi Konsultan Pajak. Jurnal Ilmiah Akuntansi dan Bisnis, 14(1), 132-141. doi:10.24843/JIAB.2019.v14.i01.p12.

Dyer, J. H. \& Nobeoka, K. (2000). Creating and Managing A HighPerformance KnowledgeSharing Network: The Toyota Case. Strategic management journal, 21(3), 345-367. doi:10.1002/ (SICI) 1097.

Frecknall-Hughes, J. \& Kirchler, E. (2015). Towards A General Theory of Tax Practice. Social \& Legal Studies, 24(2), 289-312. doi:10.1177/0964663915571787.

Glaister, K. W. \& Hughes, J. F. (2008). Corporate Strategy Formulation and Taxation: Evidence from UK Firms. British Journal of Management, 19(1), 33-48. doi:10.1111/j.1467-8551.2007.00532.x.

Glückler, J. \& Armbrüster, T. (2003). Bridging Uncertainty in Management Consulting: The Mechanisms of Trust and Networked Reputation. Organization studies, 24(2), 269-297. doi:10. $1177 / 0170840603024002346$.

Grönlund, J., Sjödin, D. R., \& Frishammar, J. (2010). Open Innovation and The Stage-Gate Process: A Revised Model for New Product Development. California management review, 52(3), 106-131. doi:10.1525\%2Fcmr.2010.52.3.106.

Hau, Y. S., Kim, B., Lee, H., \& Kim, Y.-G. (2013). The Effects of Individual Motivations and Social Capital on Employees' Tacit and Explicit Knowledge Sharing Intentions. International Journal of Information Management, 33(2), 356-366. doi:10.1016/j.jinfomgt.2012.10.009.

Hayes, S., Freudenberg, B., \& Delaney, D. (2018). Role of Tax Knowledge and Skills: What Are the Graduate Skills Required by Small to Medium Accounting Firms. J. Australasian Tax Tchrs. Ass'n, 13, 152.

Herawaty, A. \& Susanto, Y. K. (2008). Profesionalisme, Pengetahuan Akuntan Publik dalam Mendeteksi Kekeliruan, Etika Profesi, dan Pertimbangan Tingkat Materialitas. Makalah Presentasi Konferensi. The 2nd National Conference Universitas Katolik Widya Mandala Surabaya. 11 Mei. Surabaya. 
Islam, Z. M. (2010). The Mediating Effects of Socialization on Organizational Contexts and Knowledge Sharing. Journal of Knowledge globalization, 3(1), 31-48.

Ko, D. G. (2010). Consultant Competence Trust doesn't Pay Off, but Benevolent Trust Does! Managing Knowledge with Care. Journal of Knowledge Management, 14(2), 202-213. doi:10.1108/136732710110323555.

Kombih, M. T. \& Suhardianto, N. (2018). Pengaruh Aktivitas Pemasaran, Kinerja Keuangan, dan Aset tidak Berwujud terhadap Nilai Perusahaan. EKUITAS (Jurnal Ekonomi dan Keuangan), 1(3), 281-302. doi: 10.24034/j25485024.y2017.v1.i3.1909.

Krackhardt, D. (1992). The Strength of Strong Ties: The Importance of Philos in Networks and Organization in Book of Nitin Nohria and Robert G. Networks and Organizations. Cambridge: Harvard Business School Press.

Liebowitz, J. (2001). Knowledge Management and Its Link to Artificial Intelligence. Expert Systems with Applications, 20(1), 1-6. doi:10.1016/SO957-4174(00)00044-0.

Lumbantobing, P. (2011). Manajemen Knowledge Sharing Berbasis Komunitas. Bandung: Knowledge Management Society Indonesia.

Mulligan, E. \& Oats, L. (2016). Tax Professionals at Work in Silicon Valley. Accounting, Organizations and Society, 52, 63-76. doi:10.1016/j.aos.2015.09.005.

Nonaka, I. \& Teece, D. J. (2001). Managing Industrial Knowledge: Creation, Transfer, and Utilization. California: Sage.

Orr, J. E. (2016). Talking about Machines: An Ethnography of A Modern Job. New York: Cornell University Press.

Pratomo, S. A. (2017). Manajemen Aset Kekayaan Intelektual. Kiat Bisnis, 6(5).

Putra, Y. R. A. N., Indrabudiman, A., Riyadi, S., \& Handayani, W. S. (2020). Pengaruh Karakteristik Perusahaan terhadap Tax Avoidance serta Dampaknya pada Nilai Perusahaan. Jurnal Akuntansi Aktual, 71), 57-66. doi:10.17977/um004v7112020p57.

Rokeach, M. (1968). Beliefs, Attitudes and Values: A Theory Of Organization And Change. San Fransisco: Jossey-Bass.

Sila, M., Bambang, S., Zaki, B., \& Aulia Fuad, R. (2016). The Effect of Knowledge and Experience on Professional Auditor's Judgment: Study on State Auditor in Indonesia. International Journal of Management and Administrative Sciences (IJMAS), 3(10), 98-106.

Sugiyono, D. (2006). Statistika untuk penelitian. Bandung: CV. Alfabeta.

Suharyat, Y. (2009). Hubungan antara Sikap, Minat dan Perilaku Manusia. Jurnal Region, 1(3), 1-19.

Tarsidi, D. (2010). Teori Kognitif Sosial Albert Bandura. Bandung: Universitas Pendidikan Indonesia.

Van den Hooff, B. \& Huysman, M. (2009). Managing Knowledge Sharing: Emergent and Engineering Approaches. Information \& Management, 46(1), 1-8. doi:10.1016/j.im.2008.09.002.

Van der Rijt, P., Hasseldine, J., \& Holland, K. (2019). Sharing corporate tax knowledge with external advisers. Accounting and Business Research, 49(4), 454-473. doi:10.1080/00014788.2018.15260 58.

Wang, C.-C. \& Yang, Y.-J. (2007). Personality and Intention to Share Knowledge: An Empirical Study of Scientists in an R\&D Laboratory. Social Behavior and Personality: an International Journal, 35(10), 1427-1436. doi:10.2224/sbp.2007.35.

Wang, S. \& Noe, R. A. (2010). Knowledge sharing: A Review and Directions for Future Research. Human resource management review, 20(2), 115-131. doi:10.1016/j.hrmr.2009.10.001. 
Halaman ini sengaja dibiarkan kosong 